\title{
Profil klinis Infeksi Saluran Kemih pada Anak di RS Dr. Cipto Mangunkusumo
}

\author{
Miesien, Taralan Tambunan, Zakiudin Munasir
}

\begin{abstract}
Latar belakang. Infeksi saluran kemih (ISK) sering terjadi pada bayi dan anak kecil. Gejala ISK tergantung usia, intensitas reaksi inflamasi dan lokasi infeksi pada saluran kemih.

Tujuan. Mengetahui profil klinis ISK pada anak di RS Dr. Cipto Mangunkusumo.

Metode dan subyek. Desain penelitian ini adalah deskriptif potong lintang. Subyek berusia lebih dari 2 bulan sampai 13 tahun, berobat ke Departemen IKA RSCM dalam kurun waktu Februari sampai dengan Agustus 2004. Diagnosis ISK ditegakkan berdasarkan hasil biakan urin bila pertumbuhan kuman ${ }^{3} 10^{5} \mathrm{koloni} / \mathrm{ml}$ urin.

Hasil. Dalam kurun waktu 7 bulan ditemukan 50 subyek (28 laki-laki dan 22 perempuan), usia rerata dua tahun $(S D \pm 2,4)$. Terbanyak usia 2 bulan -2 tahun (32/ 50). Lima gejala klinis terbanyak adalah demam, nafsu makan menurun, diare, kencing tidak lancar dan muntah. Tiga tanda klinis terbanyak dianatarnya adalah demam, balanitis dan ikterus. Pemeriksaan penunjang sebagian besar normal.

Kesimpulan. Infeksi saluran kemih (ISK) terbanyak pada usia 2 bulan -2 tahun. Gejala klinis ISK terutama demam. Tanda klinis ISK terbanyak demam, balanitis dan ikterus. Hasil urinalisis normal tidak menyingkirkan diagnosis ISK, sehingga anak demam pada usia 2 bulan -2 tahun dengan penyebab tidak jelas perlu dipikirkan ISK.
\end{abstract}

Kata kunci: infeksi saluran kemih, profil klinis, anak.

$\mathrm{I}$ nfeksi saluran kemih (ISK) relatif sering terjadi pada bayi dan anak kecil. Menurut kepustakaan demam dengan sebab yang tidak

\footnotetext{
Alamat korespondensi:

Prof. Dr. Taralan Tambunan, $\mathrm{SpA}(\mathrm{K})$.

Divisi Nefrologi Departemen Ilmu Kesehatan anak FKUI-RSCM Jl. Salemba No 6 Jakarta 10430.

Telpon. 021-3915179

Dr. Zakiudin Munasir, Sp.A(K)

Divisi Alergi Departemen Ilmu Kesehatan anak FKUI-RSCM. Dr. Miesien.

PPDS Departemen Ilmu Kesehatan anak FKUI-RSCM 10430.

Telpon: 021-92897471, Telpon Genggam: 081380736515
}

jelas pada anak berusia 2 bulan - 2 tahun sekitar 5\% disebabkan oleh ISK dan prevalensi ISK anak perempuan pada usia ini dua kali lebih tinggi dari pada anak laki - laki. ${ }^{1-3}$ Gejala klinis ISK bervariasi tergantung kepada usia, intensitas reaksi inflamasi dan lokasi infeksi pada saluran kemih. Anak berusia 2 bulan - 2 tahun yang menderita ISK perlu mendapat perhatian khusus oleh karena gejala klinis yang tidak khas, cara mendapatkan sampel urin yang invasif, dan mempunyai risiko terbesar untuk terjadinya kerusakan ginjal. ${ }^{1-3}$

Diagnosis ISK ditegakkan berdasarkan anamnesis, pemeriksaan fisis, dan pemeriksaan penunjang, serta dipastikan dengan biakan urin kuantitatif. ${ }^{2}$ 
Infeksi saluran kemih dapat membawa dampak jangka panjang terhadap fungsi ginjal yaitu berkembangnya uremia, terjadinya hipertensi dan adanya komplikasi selama kehamilan. Dengan bervariasinya manifestasi klinis ISK maka perlu diketahui bagaimana manifestasi klinis ISK pada anak.

\section{Metoda penelitian}

Penelitian ini adalah penelitian deskriptif dengan desain potong lintang. Subyek penelitian adalah anak usia 2 bulan - 13 tahun yang didiagnosis ISK berdasarkan adanya gejala klinik ISK dan biakan urin dan berobat ke Departemen Ilmu Kesehatan Anak RSCM pada bulan Februari - Agustus 2004. Penampungan urin menggunakan kantong urin, urin pancar tengah atau dengan menggunakan kateter. Diagnosis pasti ISK ditegakkan jika terdapat pertumbuhan kuman ${ }^{3} 10^{5}$ koloni/ml urin. Darah tepi dan urinalisis dilakukan pada semua pasien. Pasien yang terbukti ISK berdasarkan biakan urin dimasukkan sebagai subyek penelitian dan dilengkapi pemeriksaan ureum, kreatinin darah dan ultrasonografi (USG) ginjal dan buli- buli.

\section{Beberapa definisi}

- Demam apabila: suhu rektal $\geq 38^{\circ} \mathrm{C}$; demam tinggi suhu rektal $\geq 39^{\circ} \mathrm{C}$. Pengukuran suhu pada penelitian ini dilakukan melalui: aksila $\left( \pm 0,5^{\circ} \mathrm{C}\right.$ lebih rendah dari rektal). ${ }^{4}$

- Urinalisis kecurigaan ISK terdiri dari eritrosituria
$>3 / \mathrm{LPB}$, leukosituria > 5/LPB, atau bakteriuria positif. $^{5}$

- Pemeriksaan darah tepi yang diteliti meliputi: jumlah leukosit, hitung jenis dan laju endap darah (LED). Jumlah leukosit dan hitung jenis dibandingkan dengan nilai normal berdasarkan umur, ${ }^{6}$ sedangkan LED meningkat jika nilai $>30 \mathrm{~mm} /$ jam pertama. ${ }^{4}$

- Status gizi dipakai kriteria berat badan/tinggi badan x 100\% (berdasarkan kriteria yang dipakai di Divisi Gizi Metabolik RSCM).

\section{Hasil}

Dalam kurun waktu 7 bulan didapatkan 50 anak dengan ISK yang terdiri dari 28 laki - laki dan 22 perempuan dengan sebaran usia antara dua bulan sampai dengan 13 tahun dan usia rerata dua tahun $(S D \pm 2,4)$. Pada tabel 1 dapat dilihat bahwa usia penderita ISK terbanyak adalah kelompok usia 2 bulan - 2 tahun (32/50). Tinggi badan $<\mathrm{P}_{5}$ NCHS terdapat pada 11 anak di antara 30 subyek yang diperiksa sedangkan status gizi pada sebagian besar subyek merupakan gizi kurang (17/30).

Pada tabel 2 dapat dilihat bahwa lima gejala klinis terbanyak adalah riwayat demam (36/50), nafsu makan menurun $(28 / 50)$, diare $(21 / 50)$, kencing tidak lancar (17/50) dan muntah (15/50). Demam $\geq 2$ hari didapatkan pada 34/50 anak. Kelompok usia yang terbanyak mengalami demam adalah kelompok usia 2 bulan -2 tahun (22/50).

Tabel 1. Karakteristik subyek

\begin{tabular}{|c|c|c|c|c|c|}
\hline & & & Jenis I & & Jumlah \\
\hline Kara & istik st & $(\mathbf{n})$ & Laki - laki & Perempuan & \\
\hline Usia & (50) & 2 bulan -1 tahun & 9 & 8 & 17 \\
\hline & & $>1-2$ tahun & 7 & 8 & 15 \\
\hline & & $>2-5$ tahun & 10 & 4 & 14 \\
\hline & & $>5$ tahun & 2 & 2 & 4 \\
\hline Tinggi badan & (30) & $\geq \mathrm{P}_{5} \mathrm{NCHS}$ & & & 19 \\
\hline & & $<\mathrm{P}_{5} \mathrm{NCHS}$ & & & 11 \\
\hline Status gizi & (30) & Kurang & & & 17 \\
\hline & & Baik & & & 7 \\
\hline & & Buruk & & & 2 \\
\hline & & Lebih & & & 2 \\
\hline & & Obesitas & & & 2 \\
\hline
\end{tabular}


Pada tabel 3 dapat dilihat bahwa dari tiga tanda klinis terbanyak yang didapatkan pada pemeriksaan fisis yaitu demam dengan suhu $\geq 38^{\circ} \mathrm{C}$ sebanyak (28/ 50), balanitis (10/28 subyek laki - laki) dan ikterus lima dari 50 subyek.

Tabel 4 memperlihatkan bahwa kelainan pada hasil pemeriksaan penunjang dilakukan pada kurang dari 50\% sample, kecuali hitung jenis yang sebagian besar segmenter.

\section{Diskusi}

Infeksi saluran kemih mempunyai gejala klinis yang bervariasi tergantung kepada usia, intensitas reaksi inflamasi dan lokasi infeksi pada saluran kemih.
Subyek penelitian terbanyak berusia 2 bulan -2 tahun (32/50), setelah usia 1 tahun terdapat kecenderungan penurunan jumlah pasien ISK (Tabel 1). Hal ini sesuai dengan kepustakaan menyebutkan bahwa ISK banyak terjadi pada anak berusia 2 bulan 2 tahun dan terbanyak terjadi pada 1 tahun pertama. Pada penelitian ini tidak dimasukkan penderita ISK pada usia $<2$ bulan sehingga dapat diperkirakan jumlah ISK pada usia 1 tahun pertama jauh lebih tinggi dari data yang didapatkan. Pada kelompok usia 2 bulan - 2 tahun jumlah laki - laki sama dengan jumlah subyek perempuan. Hal ini berbeda dengan kepustakaan yang menyebutkan bahwa jumlah subyek perempuan pada kelompok usia 2 bulan - 2 tahun dua kali lipat dibandingkan dengan jumlah laki - laki karena pendeknya uretra. ${ }^{1,2,7}$ Perbedaan ini tidak dapat

Tabel 2. Sebaran gejala klinis berdasarkan kelompok usia

\begin{tabular}{|c|c|c|c|c|c|c|}
\hline \multirow{2}{*}{\multicolumn{2}{|c|}{ Gejala klinis }} & \multicolumn{4}{|c|}{ Kelompok usia } & \multirow{2}{*}{$\begin{array}{c}\text { Jumlah } \\
\mathrm{n}=50\end{array}$} \\
\hline & & $2 \mathrm{bl}-1$ th & $>\left(\begin{array}{ll}1 & -2\end{array}\right)$ th & $>(2-5)$ th & $>5$ th & \\
\hline Demam & $<2$ & & 2 & & & 2 \\
\hline \multirow[t]{2}{*}{ (hari) } & $2-7$ & 5 & 6 & 5 & 1 & 17 \\
\hline & $>7$ & 6 & 3 & 5 & 3 & 17 \\
\hline \multicolumn{2}{|c|}{ Nafsu makan menurun } & 7 & 10 & 7 & 4 & 28 \\
\hline \multicolumn{2}{|c|}{ Diare } & 5 & 7 & 7 & 2 & 21 \\
\hline \multicolumn{2}{|c|}{ Kencing tidak lancar } & 7 & 8 & 1 & 1 & 17 \\
\hline \multicolumn{2}{|c|}{ Muntah } & 2 & 7 & 5 & 1 & 15 \\
\hline \multicolumn{2}{|c|}{ Mual } & 1 & 5 & 6 & & 12 \\
\hline \multicolumn{2}{|c|}{ Menangis jika berkemih } & 3 & 2 & 4 & 1 & 10 \\
\hline \multicolumn{2}{|c|}{ Cengeng } & 3 & 2 & 4 & 1 & 10 \\
\hline \multicolumn{2}{|c|}{ Nyeri perut } & & 6 & 1 & 7 & \\
\hline \multicolumn{2}{|c|}{ Sering berkemih } & & & 4 & & 4 \\
\hline \multicolumn{2}{|c|}{ Konstipasi } & & 2 & & & 2 \\
\hline \multicolumn{2}{|c|}{ Inkontinensia urin } & & & 1 & & 1 \\
\hline
\end{tabular}

Tabel 3. Pemeriksaan fisis

\begin{tabular}{|c|c|c|c|c|c|c|}
\hline \multirow{2}{*}{\multicolumn{2}{|c|}{ Pemeriksaan fisis }} & \multicolumn{4}{|c|}{ Kelompok usia } & \multirow[t]{2}{*}{ Jumlah } \\
\hline & & $2 \mathrm{bl}-1$ th & $>\left(\begin{array}{ll}1 & -2\end{array}\right)$ th & $>(2-5)$ th & $>5$ th & \\
\hline Suhu & $<38$ & 10 & 5 & 6 & \multirow{3}{*}{4} & 21 \\
\hline \multirow[t]{2}{*}{$\left({ }^{\circ} \mathrm{C}\right)$} & $38-<39$ & 4 & 4 & 4 & & 16 \\
\hline & $\geq 39$ & 3 & 5 & 4 & & 12 \\
\hline \multicolumn{2}{|c|}{ Tensi normal $(\mathrm{n}=10)$} & 4 & 1 & 5 & \multirow{5}{*}{1} & 10 \\
\hline \multicolumn{2}{|c|}{ Ikterus $(\mathrm{n}=50)$} & 5 & & & & 5 \\
\hline \multicolumn{2}{|c|}{ Balanitis $(\mathrm{n}=28)$} & 3 & 3 & 3 & & 10 \\
\hline \multicolumn{2}{|c|}{ Vulvitis $(\mathrm{n}=22)$} & 1 & 1 & 1 & & 3 \\
\hline Perlek: & ia $(n=22)$ & 2 & & & & 2 \\
\hline
\end{tabular}


Sari Pediatri, Vol. 7, No. 4, Maret 2006

Tabel 4. Pemeriksaan penunjang

\begin{tabular}{|c|c|c|c|}
\hline \multicolumn{2}{|c|}{ Jenis pemeriksaan } & \multirow{2}{*}{$\begin{array}{l}\text { Hasil pemeriksaan } \\
\text { Meningkat }\end{array}$} & \multirow{2}{*}{$\begin{array}{c}\text { Proporsi } \\
4\end{array}$} \\
\hline Darah tepi & Jumlah leukosit $(n=40)$ & & \\
\hline & Hitung jenis $(n=28)$ & Segmenter & 22 \\
\hline & $\operatorname{LED}(\mathrm{mm} / \mathrm{jam})(\mathrm{n}=21)$ & Meningkat & 8 \\
\hline \multirow{3}{*}{$\begin{array}{l}\text { Urinalisis } \\
(\mathrm{n}=50)\end{array}$} & Jumlah leukosit & Meningkat (>5) & 11 \\
\hline & Jumlah eritrosit & Meningkat (>3) & 6 \\
\hline & Bakteri & $(+)$ & 6 \\
\hline \multirow{2}{*}{$\begin{array}{l}\text { Fungsi ginjal } \\
(\mathrm{n}=15)\end{array}$} & Ureum & Meningkat $(34 \mathrm{mg} / \mathrm{dL})$ & 1 \\
\hline & Kreatinin & Meningkat (>1mg/dL) & 0 \\
\hline \multirow{6}{*}{$\begin{array}{l}\text { Ultrasonografi } \\
(\mathrm{n}=21)\end{array}$} & & Normal & 15 \\
\hline & & Pielonefritis & 2 \\
\hline & & Uremic kidney & 1 \\
\hline & & Batu ginjal kanan & 1 \\
\hline & & Pieloektasis ginjal kanan & 1 \\
\hline & & Hidronefrosis dan hidroureter bilateral & 1 \\
\hline
\end{tabular}

diterangkan dengan pasti, kemungkinan ada hubungannya dengan budaya membersihkan daerah genital di Indonesia berbeda dengan di negara barat. Di Indonesia terdapat kebiasaan membersihkan daerah genital dengan menggunakan air sesudah berkemih (cebok) sehingga terjadi dilusi sedangkan di negara barat dengan menggunakan kertas (toilet paper). Kemungkinan lain adalah prepusium pada anak laki - laki mempermudah kolonisasi kuman uropatogen di bawah prepusium. ${ }^{8}$

Subyek dengan tinggi badan $<$ P5 NCHS terdapat 11 dari 30 subyek. Hal ini kemungkinan bukan disebabkan oleh ISK tetapi oleh status nutrisi yang terganggu sebelum menderita ISK, karena tinggi badan baru terpengaruh jika terjadi kurang gizi yang bersifat kronis atau terjadi gagal ginjal kronis. Hal ini didukung oleh hasil pemeriksaan fungsi ginjal yang masih dalam batas normal. Penelitian anak sekolah dasar di Padang mendapatkan prevalensi anak dengan perawakan pendek $\left(<\mathrm{P}_{3} \mathrm{NCHS}\right) 19 \%$, sedangkan pada anak SMP $16,74 \% .{ }^{9}{ }^{10}$ Saleh dkk $(2003)^{11}$ dari negara Kuwait dengan status ekonomi lebih baik, hanya mendapatkan $1,2 \%$ dari 147 subyek penelitian dengan pertumbuhan terhambat dan $6,1 \%$ subyek dengan berat badan kurang.

Sebagian besar pasien pada penelitian ini menderita gizi kurang (17/30), hal ini kemungkinan selain disebabkan oleh status nutrisi sebelum menderita ISK juga dapat disebabkan oleh ISK yang terjadi. Infeksi saluran kemih yang terjadi dapat menyebabkan terjadinya penurunan status nutrisi karena pada sebagian besar subyek terdapat keluhan demam sehingga metabolisme meningkat, nafsu makan menurun, diare, mual dan muntah yang mempengaruhi asupannya. Penelitian di Surabaya mendapatkan status gizi kurang (BB/TB) 32\% pada kondisi awal pasien saat datang ke rumah sakit. ${ }^{12}$

Lima gejala klinis terbanyak yang didapatkan ialah riwayat demam (36/50), nafsu makan menurun (28/ 50), diare (21/50), kencing tidak lancar (17/50) dan muntah (15/50). Gejala lain berdasarkan urutan terbanyak adalah mual, sering berkemih, rewel (cengeng), menangis atau sakit jika berkemih, nyeri perut, konstipasi dan inkontinensia urin. Gejala nyeri pinggang dan air kemih berbau busuk tidak didapatkan. Disebutkan di kepustakaan bahwa pada anak berusia 2 bulan - 2 tahun, demam sering merupakan satu - satunya gejala klinis, sedangkan gejala lain seperti nafsu makan menurun, diare, muntah, nyeri perut dan konstipasi, kadang - kadang didapatkan. ${ }^{2,13}$ Keluhan nyeri saat berkemih dan sering berkemih jarang didapatkan pada anak berusia $<2$ tahun, sedangkan keluhan nyeri pinggang jarang didapatkan pada anak yang berusia kurang dari 4 tahun. ${ }^{1-3}$

Nusarintowati dkk (2005), ${ }^{14}$ mendapatkan demam pada $12 / 15$, gejala saluran kemih pada $4 / 15$ dan diare 
pada dua dari 15 subyek. Saleh dkk (2003), ${ }^{11}$ mendapatkan gejala demam $20,3 \%$, demam yang disertai dengan gejala ISK bawah $60,8 \%$, gejala ISK bawah saja 9,5\% dan gejala di luar saluran kemih 5,4\%. Demam terbanyak pada kelompok usia 2 bulan - 2 tahun (22/50). Demam $\geq 2$ hari terdapat pada 34/50 sedangkan demam $>7$ hari pada $17 / 50$ subyek. Kepustakaan menyebutkan beberapa gejala yang menunjukkan adanya ISK pada anak perempuan usia 2 bulan - 2 tahun dengan demam di antaranya adalah demam dengan suhu $\geq 39^{\circ} \mathrm{C}$, lama demam ${ }^{3} 2$ hari dan usia $\leq 1$ tahun. Jika didapatkan ${ }^{3} 2$ kriteria maka sensitifitas kemungkinan menderita ISK mencapai 95\% dan spesifitas $31 \% .{ }^{15,16} \mathrm{Pada}$ penelitian ini didapatkan $9 / 22$ subyek perempuan dengan minimal 2 kriteria tersebut.

Beberapa kepustakaan menyebutkan bahwa pemeriksaan fisis pada kasus ISK berusia 2 bulan -2 tahun selain demam, jarang ditemukan kelainan. Kelainan yang mungkin ditemukan adalah ikterus, nyeri ketok sudut kosto vertebra, terdapat pembesaran ginjal, teraba kandung kemih, teraba skibala, vulvitis, iritasi benda asing, balanitis, striktur uretra, fimosis dan perlekatan labia. Tiga tanda klinis terbanyak yang didapatkan pada penelitian ini adalah demam dengan suhu $\geq 38^{\circ} \mathrm{C}$ sebanyak $28 / 50$, balanitis $10 / 28$ dan ikterus $5 / 50$ subyek. Saleh dkk (2003) ${ }^{11}$ mendapatkan pemeriksaan fisis normal pada $78,4 \%$, edema $16 \%$, nyeri suprapubis $2,7 \%$, nyeri pinggang $0,7 \%$ dan hipertensi $2 \%$ dari total 148 subyek penelitian.

Kenaikan suhu $\geq 39^{\circ} \mathrm{C}$ terbanyak pada kelompok usia 2 bulan - 2 tahun yaitu pada delapan dari 50 subyek. Pada kepustakaan disebutkan bahwa pasien ISK yang berusia 2 bulan - 2 tahun dengan suhu ${ }^{3}$ $39^{\circ} \mathrm{C}$ dihubungkan dengan terjadinya pielonefritis. Berdasarkan hal tersebut maka kemungkinan pielonefritis pada subyek penelitian terbanyak terjadi pada usia 2 bulan - 2 tahun. Pada pielonefritis akut dapat ditemukan peningkatan jumlah leukosit dan LED. Pada penelitian ini leukositosis terdapat empat dari 40 subyek, hitung jenis segmenter pada 22/28 dan LED pada delapan dari 21 subyek. Saleh dkk (2003), ${ }^{11}$ mendapatkan jumlah leukosit $>15000 / \mathrm{mL}$ sebanyak $27,7 \%$ dan peningkatan LED 29\% dari 148 subyek penelitian. Fimosis pada penelitian ini didapatkan cukup banyak namun karena terdapat kerancuan dalam menginterpretasi fimosis maka dikeluarkan dari penelitian ini. Balanitis pada penelitian ini didapatkan pada 10/28 subyek laki - laki. Ikterus sebagai manifestasi klinis ISK dapat disebabkan oleh hemolisis, hepatitis toksik atau gangguan hepatoselular yang disebabkan oleh endotoksin. ${ }^{17-19}$ Ikterus pada penelitian ini didapatkan pada lima dari 50 subyek. $\mathrm{Ng}$ dkk (1971) ${ }^{17}$ menemukan enam pasien dalam waktu 6 bulan yang datang ke rumah sakit dengan manifestasi ikterus. Garcia dan Nager $(2002)^{18}$ mendapatkan ISK pada $7,5 \%$ subyek dengan asymptomatic jaundice. Oswari dkk $(2005)^{19}$ mendapatkan prevalensi ISK pada kolestasis intrahepatik sebesar (24/34).

Hematuria, leukosituria $>5 / \mathrm{LPB}$ atau bakteriuria dapat terjadi pada ISK. ${ }^{2,13}$ Pada penelitian ini didapatkan lekosituria $>5 / \mathrm{LPB}$ sebanyak 11/50, sedangkan eritrosituria $>3 / \mathrm{LPB}$ dan bakteriuria $(+)$ didapatkan pada enam dari 50 subyek. Saleh dkk (2003), ${ }^{11}$ mendapatkan leukosituria $\geq 10 / \mathrm{LPB}$ sebanyak 9,3\%, hematuri 4,7\% tetapi tidak disebutkan berapa jumlah eritrosit/LPB dan bakteriuria 18\%. Nusarintowati dkk (2005), ${ }^{14}$ mendapatkan leukosituria $>$ 5/LPB pada sembilan dari 20 sampel.

Menurut Associaton of American Pediatrics (AAP) terdapat rentang yang luas pada laporan hasil urinalisis. Hasil urinalisis negatif tidak dapat menyingkirkan kemungkinan diagnosis ISK, karena hasil urinalisis sangat dipengaruhi oleh volume urin, kecepatan dan lamanya urin diputar serta ketrampilan petugas. Hasil urinalisis yang terbaik didapatkan jika dikerjakan oleh petugas yang trampil pada urin segar (dikerjakan sekitar $30-60$ menit sesudah urin ditampung) dan dilakukan kombinasi pemeriksaan esterase leukosit, nitrit dan pemeriksaan leukosit urin serta pewarnaan Gram dengan menggunakan mikroskop. ${ }^{2,13,20}$

Kerusakan ginjal akan semakin besar terjadi dengan semakin seringnya mengalami ISK. ${ }^{1,2}$ Dari 15 subyek yang diperiksa kadar ureum dan kreatinin darah hampir semuanya normal kecuali satu subyek mempunyai kadar ureum darah $34 \mathrm{mg} / \mathrm{dL}$. Hal ini berbeda dengan penelitian Saleh dkk (2003), ${ }^{11}$ yang mendapatkan kadar ureum darah $>10 \mathrm{mmol} / \mathrm{L}$ (normal $1,8-6,4 \mathrm{mmol} / \mathrm{L}$ ) sebanyak $18,2 \%$, hal ini disebabkan karena 103 dari 148 subyek penelitian telah mengalami kekambuhan 1 - > 3 kali.

Hasil pemeriksaan USG pada 21 kasus yang diteliti sebagian besar adalah normal (15/21), sedangkan sisanya didapatkan dua subyek dengan pielonefritis, dan empat dari 21 subyek yang diperiksa dengan kelainan anatomi masing - masing satu subyek dengan uremic kidney, batu ginjal kanan, hidronefrosis dan 
hidroureter bilateral serta pieloektasis ginjal kanan. Penelitian Zamir dkk (2004) yang dikutip dari Watson (2004), ${ }^{21}$ mendapatkan kelainan hasil USG pada $14 \%$ dari 255 subyek yang diperiksa, sedangkan 14,9\% terdapat kelainan MSU yang dalam pemeriksaan USG hasilnya normal.

\section{Kesimpulan}

Infeksi saluran kemih terbanyak pada usia 2 bulan - 2 tahun. Gejala klinis ISK terutama adalah demam sedangkan tanda klinis ISK selain demam dapat ditemukan balanitis dan ikterus. Hasil urinalisis normal tidak menyingkirkan diagnosis ISK, sehingga pasien demam pada usia antara 2 bulan - 2 tahun dengan sebab tidak jelas perlu dipikirkan ISK.

\section{Daftar Pustaka}

1. Hansson S, Jodal U. Urinary tract infection. Dalam: Barrat TM, Avner ED, penyunting . Pediatric nephrology, edisi ke - 4. Baltimore: Lippincott Williams \& Wilkins, 1999. h. 835-50.

2. American Academy of Pediatrics. Committee on quality improvement, subcommittee on urinary tract infection. Practice parameter. The diagnosis, treatment, and evaluation of the initial urinary tract infection in febrile infants and young children. Pediatrics 1999; 103: 843-52.

3. Tambunan T. Infeksi saluran kemih. Naskah lengkap kuliah umum PIT IDAI I Palembang. IDAI, 2001. h. 111-34.

4. Powel KR. Fever without a focus. Dalam: Behrman RE, Kliegman RM, Jenson HB, penyunting. Nelson text book of pediatrics, edisi ke -17 . Philadelphia. Saunders; 2004. h. 841-6.

5. Alatas H. Evaluasi fungsi ginjal. Dalam Alatas $H$, Tambunan T, Trihono PP penyunting. Nefrologi anak jilid 1. Jakarta. Balai penerbit 1993. h. 34-52.

6. Lanzkowsky P. Hematologic reference values. Dalam: Manual of pediatric haematology and oncology, edisi ke-2. New York. Churchill livingstone. 1995. h. 62950.

7. Jones KV, Asscher AW. Urinary tract infection and vesico - ureteral reflux. Dalam: Edelmann CM, Bernstein J, Meadow SR, Spitzer A, Travis LB, penyunting. Pediat- ric kidney disease, edisi ke-2. Boston: Little Brown, 1992. h. 1943-91.

8. Polito C, Rambaldi PF, Mausi L, Toro RD, Manna Al. Association of medical school pediatric department chairs, Inc. Unilateral vesico ureteric reflux: low prevalence of contralateral renal damage. Pediatrics 2001; 138: 875-9.

9. E R, YE, Rini EA. Prevalence of short stature in elementary school students in Padang 2005. Dalam : Garna H, Nataprawira HMD, Alam A, penyunting. Abstract book $13^{\text {th }}$ National Congress of Child Health KONIKA XIII. Bandung. Small \& Smart 2005. h. 353.

10. Rachmawati N, Marhefdison, Rini EA. Prevalence of short stature in junior high school students in Padang 2005. Dalam: Garna H, Nataprawira HMD, Alam A, penyunting. Abstract book $13^{\text {th }}$ National Congress of Child Health KONIKA XIII. Bandung. Small \& Smart 2005. h. 9.

11. Saleh SI, Tuhmaz MM, Sarkhouh MY, Ghawabi MA. Urinary tract infection in infants and children in $\mathrm{Al}$ Jahra area, Kuwait: an overview. Kuwait Med J 2003; 35: 31-5.

12. HMA R, IR, H SN, H B. The incidence of hospital malnutrition in pediatric ward DR. Soetomo hospital Surabaya. Dalam : Garna H, Nataprawira HMD, Alam A, penyunting. Abstract book $13^{\text {th }}$ National Congress of Child Health KONIKA XIII. Bandung. Small \& Smart 2005. h. 254.

13. Santen SA, Altieri MF. Pediatric urinary tract infection. Emerg Med Clin North Am 2001; 19: 675-90.

14. Nusarintowati, Trihono PP, Pardede SO. Clinical features of urinary tract infectin in pediatric ward Ciptomangunkusumo hospital. Abstact book $13^{\text {th }} \mathrm{Na}$ tional Congress of Child Health KONIKA XIII. Bandung. Small \& Smart 2005. h. 158.

15. Gorelick MH, Shaw KN. Clinical decision rule to identity febrile young girls at risk for urinary tract infection. Arch Pediatr Adolsc Med 2000; 154: 386-90.

16. Newman TB, Bernzweig JA, Takayama JI, Finch SA, Wasserman RC and Pantell RH . Urin testing and urinary tract infections in febrile infants seen in office settings. Arch Pediatr Adolesc Med 2002; 156: 44-54.

17. NG, SH, Rawstron. Urinary tract infections presenting with jaundice. Arch Dis Child 1971;46: 173-6.

18. Garcia FJ, Nager AL. Jaundice as an early diagnostic sign of urinary tract infection in infancy. Pediatrics 2002; 109: 846-51.

19. Oswari H, Harijadi, Bisanto J, SP Purnamawati. Infeksi 
saluran kemih sebagai penyebab kolestasis intrahepatik. Sari pediatri 2005;6: 166-171.

20. Alatas H. Evaluasi fungsi ginjal. Dalam Alatas H, Tambunan T, Trihono PP penyunting. Nefrologi anak jilid 1. Jakarta. Balai penerbit 1993. h. 34-52.
21. Zamir G, Sakran W, Horowitz Y, Koren A, Miron D. Urinary tract infection: is there a need for routine renal ultrasonography?. Arch Dis Child 2004; 89:466-8 dikutip dari Watson AR. Pediatric urinary tract infection. EAU Update Series 2004;2: 94-100. 